\title{
Fracture resistance of rubbers with MWCNT, organoclay, silica and carbon black fillers as assessed by the J-integral: Effects of rubber type and filler concentration
}

\author{
S. Agnelli ${ }^{*}$, G. Ramorino ${ }^{1}$, S. Passera ${ }^{1}$, J. Karger-Kocsis ${ }^{2}$, T. Ricco ${ }^{1}$ \\ ${ }^{1}$ Dipartimento di Ingegneria Meccanica e Industriale, Facoltà di Ingegneria, Università degli Studi di Brescia, via \\ Branze 38, I-25123 Brescia, Italy \\ ${ }^{2}$ Department of Polymer Engineering, Faculty of Mechanical Engineering, Budapest University of Technology and \\ Economics, H-1111 Budapest, Hungary
}

Received 3 November 2011; accepted in revised form 30 January 2012

\begin{abstract}
The fracture resistance of different rubbers containing various nanofillers, such as multiwall carbon nanotube (MWCNT), organoclay, silica and carbon black (CB), was determined by the J-integral making use of the single edge notched tensile loaded (SEN-T) single specimen approach. The elastomeric matrices were natural (NR), ethylene propylene diene (EPDM) and hydrogenated nitrile rubbers (HNBR). Moreover, the strain softening (Payne effect) of selected rubbers with 30 part per hundred rubber (phr) filler content was also investigated by dynamic mechanical thermal analysis (DMTA) in shear mode. DMTA results indicated that the Payne effect follows the ranking: MWCNT(fibrous) $>$ organoclay (platy) $>$ silica(spherical). J-resistance $\left(J_{\mathrm{R}}\right)$ curves were constructed by plotting the $J$ value as a function of the crack tip opening displacement $\left(\mathrm{CTOD}^{\star}\right)$, monitored during loading. $\mathrm{CTOD}^{\star}=0.1 \mathrm{~mm}$ was considered as crack initiation threshold and thus assigned to the critical value $J_{\text {Ic }}$. $J_{\text {Ic }}$ increased with increasing filler loading, whereby MWCNT outperformed both silica and CB. On the other hand, $J_{\text {Ic }}$ did not change with filler loading for the NR/organoclay systems that was traced to straininduced crystallization effect in NR. The tearing modulus $\left(T_{\mathrm{J}}\right)$ also increased with increasing filler loading. The related increase strongly depended on both rubber and filler types. Nonetheless, the most prominent improvement in $T_{\mathrm{J}}$ among the fillers studied was noticed for the fibrous MWCNT.
\end{abstract}

Keywords: rubber, nanocomposite, fracture mechanics, J-resistance curve

\section{Introduction}

The use of novel nanoparticles in rubber compounding is one of the latest trends in the development of elastomeric materials. Nanofillers such as carbon nanotubes (CNT), organophilic modified clays are very attractive because they can improve mechanical, thermal and physical properties even in small amounts, once provided that a good dispersion in the matrix is obtained and a good matrixfiller interaction is achieved [1-3]. In fact if the filler is dispersed on a nanometer scale, its surface area is increased so much that its efficiency exceeds that of conventional non-active fillers. On the other hand, the effect of the novel nanofillers is somewhat similar to those of the traditional active fillers, i.e. silica and carbon black (CB).

Among nanofillers, CNTs are very promising for their outstanding mechanical properties and for their high thermal and electrical conductivity. On the other side, when used as fillers in a polymeric matrix, difficulties rise in obtaining a good CNT dispersion with common processing technologies. Multiwall carbon nanotube (MWCNT) reinforced composites are widely investigated in literature,

\footnotetext{
${ }^{*}$ Corresponding author, e-mail: silvia.agnelli@ing.unibs.it
} (c) BME-PT 
and although a large body of work has already been done on mechanical properties of MWCNT filled elastomers $[1,2]$, their fracture behaviour is still unexplored.

This work is aimed at investigating the reinforcing effect promoted by MWCNT, organoclay, silica and $\mathrm{CB}$ nanoparticles on fracture resistance of various rubbers. The elastomeric matrices selected were: natural rubber (NR), ethylene propylene diene (EPDM), and hydrogenated nitrile butadiene rubber (HNBR). NR was filled with organoclay, EPDM with CB and HNBR both with MWCNT and silica. In all systems the amount of filler has been varied. The fracture resistance of the various materials was studied by using the J-integral which is a fracture mechanical approach. The single specimen J-testing methodology was recently adapted for rubbers $[4,5]$. Fracture mechanics parameters describe quantitatively the material resistance to fracture in the presence of flaws or defects, and $J$ parameter can be defined as the energy required per unit area to create new fracture surfaces. The peculiar feature of the J-testing is that one can get information on both the resistance to crack initiation and to propagation in the materials.

\section{Experimental}

\subsection{Materials}

The sulphur-cured NR (SMR-GP) was filled with different amounts of an organoclay consisting in montmorillonite modified with dimethyl dihydrogenated tallow ammonium salt and with an organic content of $40 \mathrm{wt} \%$ (Dellite $67 \mathrm{G}$, produced by Laviosa Chimica Mineraria SpA (Livorno, Italy)). The following amounts of organoclay were added in the NR matrix: $0,6.5,14$ and 30 parts per hundred rubber (phr). The preparation and the recipe of NR-based nanocomposites, kindly prepared and supplied by Pirelli SpA (Milan, Italy), were published in ref. [5-7]. The sulphur-cured EPDM rubber was filled with different amounts of CB N550 type. $\mathrm{CB}$ was added in $0,30,45$ and $60 \mathrm{phr}$ in the related recipes the preparation of which was disclosed earlier [8]. The peroxide cured HNBR contained two different amounts (viz. 10 and $30 \mathrm{phr}$ ) of silica nanoparticles or MWCNTs, respectively. Silica under the trade name Ultrasil VN2 was procured from Evonik-Degussa (Essen, Germany), whereas the MWCNT (Baytubes C 150 P) was supplied by
Table 1. Summary of matrices and filler types and contents of the materials studied

\begin{tabular}{|l|l|c|}
\hline \multicolumn{1}{|c|}{ Matrix } & \multicolumn{1}{c|}{ Filler type } & Filler contents [phr] \\
\hline HNBR & Silica & $0 ; 10 ; 30$ \\
\hline HNBR & MWCNTs & $0 ; 10 ; 30$ \\
\hline EPDM & CB & $0 ; 30 ; 45 ; 60$ \\
\hline NR & Organoclay & $0 ; 6.5 ; 14 ; 30$ \\
\hline
\end{tabular}

Bayer MaterialScience (Leverkusen, Germany). The composition and preparation of the HNBRbased systems were already published $[9,10]$. The materials for testing were available form of ca. $2 \mathrm{~mm}$ thick vulcanized plates. A summary of matrices and fillers of all the materials shown is reported in Table 1.

\subsection{Tests}

Preliminarily, some basic mechanical properties were measured at low strains, in order to provide additional information about of the different mechanical behavior of the various materials. Tensile tests were performed on CB filled EPDM rubbers, to evaluate the stress-strain curves of the material and measure the initial modulus. Such tests were carried out by an Instron dynamometer (Model 3366, INSTRON, Norwood, Massachusetts, USA), at the crosshead speed of $5 \mathrm{~mm} / \mathrm{min}$ on $10 \mathrm{~mm}$ large and $2 \mathrm{~mm}$ thick strips, with a gauge length of $60 \mathrm{~mm}$. Due to the small amount of material available, the HNBR based composites were not characterized by tensile tests, but by dynamic mechanical tests, performed in shear mode, at room temperature, at the frequency of $1 \mathrm{~Hz}$ in a shear strain amplitude range between 0.001 and 0.1 . These tests were performed by a dynamic-mechanical thermal analyser (DMTA) by Polymer-Lab Ltd. (Loughborough, UK). The aim behind dynamic mechanical tests was merely a basic characterization of the mechanical behavior of such materials (stiffness at low strains, non-linearity effects, dissipative properties), completely unrelated to the results of fracture tests shown in this work. Fracture tests are performed on single edge notched in tension loaded (SENT) specimens (see Figure 1a).

The width $(W)$ is $25 \mathrm{~mm}$, the thickness $(B)$ is $2 \mathrm{~mm}$, the gauge length $(L)$ is $50 \mathrm{~mm}$ and the initial crack length $\left(a_{0}\right)$ to width ratio was 0.4 . Such dimensions were chosen on the basis of a previous work aimed at optimizing the geometry factor [5]. The notch is introduced by an industrial blade and then sharp- 


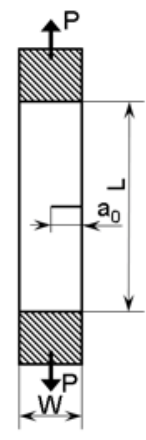

a)

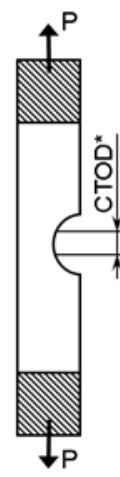

b)

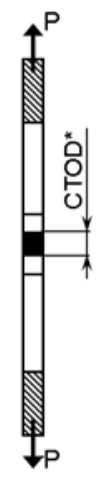

c)

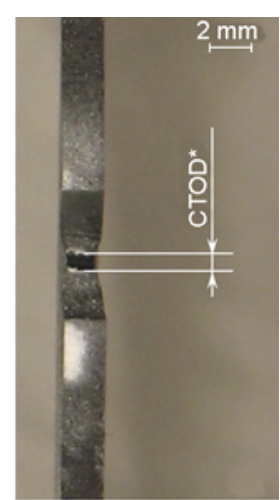

d)
Figure 1. a) geometry of SENT specimen used for fracture tests; b), c) schematic representation of the loaded specimen in a lateral and a frontal view, respectively; d) photo of the crack tip of a specimen of HNBR filled with $10 \mathrm{phr}$ MWCNTs in a frontal view; $\mathrm{CTOD}^{\star}$ is indicated

ened by sliding a razor blade at the notch tip. Tests were carried out by an Instron dynamometer (the same used for tensile tests), at the crosshead speed of $2 \mathrm{~mm} / \mathrm{min}$ at room temperature. The fracture testing methodology employed was introduced in details in ref. [5]. Recall that this J-testing methodology allows us to detect the fracture initiation point from which the material resistance to crack initiation $\left(J_{\text {Ic }}\right)$ can be deduced, and also to assess the stable crack propagation by constructing the J-resistance curve, and all this by testing only one specimen. Practically, while the load-displacement data are recorded, a photo camera takes a sequence of photos of the crack tip, one every 5 seconds. The camera is positioned in front of the crack in order to focus on the internal surfaces of the crack. A schematic representation of a specimen during the fracture process is shown in fig. 1, both from a lateral view (Figure 1b) and from the corresponding frontal view (Figure 1c), while Figure 1d shows a real picture taken to the specimen in a frontal view. The crack surfaces are coated by a contrast powder (e.g.: talc for black materials) before the test and therefore the new fracture surfaces can be easily recognised because of the contrast between the colour of rubber and the colour of the powder. By analysing such photos the point where fracture begins to propagate can be detected, and the $J$ value corresponding to the onset of fracture $\left(J_{\mathrm{Ic}}\right)$ can be evaluated by Equation (1):

$J=\frac{\eta \cdot U}{B \cdot\left(W-a_{0}\right)}$ where $U$ is energy, evaluated as the area under the load-displacement curve up to the point considered, and $\eta$ is a geometry factor, equal to 0.9 [5]. The resistance of the specimen to fracture propagation is characterized by the J-resistance curve, which relates $J$, evaluated by the loading curve following Equation (1), to the crack advancement $(\Delta a)$ during the phase of stable crack advancement. However, high deformability of rubbers makes impossible to monitor the actual crack advancement during the test. The methodology followed in this work relates $J$ values to the crack tip opening displacement, $\mathrm{CTOD}^{\star}$, at different times during the fracture process. $\mathrm{CTOD}^{\star}$ is related to the crack advancement, and can be therefore considered as an indirect measurement of $\Delta a$. $\mathrm{CTOD}^{\star}$ is measured on the pictures taken to the crack tip in a frontal view, where the extension of the opening at the crack tip $\left(\mathrm{CTOD}^{\star}\right)$ due to the creation of the new fracture surfaces is evidenced by the contrast of the different colors of rubber and coating powder. An example of $\mathrm{CTOD}^{\star}$ measurement is shown in Figure 1c and $1 \mathrm{~d}$. In the present work the correlation between $\mathrm{CTOD}^{\star}$ and $\Delta a$ was not analyzed. A CTOD ${ }^{\star}-\Delta a$ calibration curve was however obtained by the authors for a CB filled HNBR by a multi-specimen procedure. The result, shown in ref. [11], evidenced that $\mathrm{CTOD}^{\star}$ was linearly dependent on $\Delta a$ in the first stage of the fracture process of the elastomeric system investigated. It should be pointed out that often it was not possible to identify unequivocally the onset of crack advancement, but rather a gradual transition was observed from the phase of deformation to the phase of fracture at the crack tip. For this reason the initiation point was rendered to $\mathrm{CTOD}^{\star}=0.1 \mathrm{~mm}$ (through the whole thickness). Each fracture test was repeated three times.

\section{Results and discussion}

The storage shear $\left(G^{\prime}\right)$ and the loss shear modulus $\left(G^{\prime \prime}\right)$ resulting from the DMTA tests are plotted in Figure 2 and 3, respectively, as a function of the shear strain amplitude for the NR and HNBR with and without $30 \mathrm{phr}$ additives.

$G^{\prime}$ and $G^{\prime \prime}$ of neat HNBR are indicated by full squares, while full circles and full triangles indicate HNBR filled with $30 \mathrm{phr}$ of silica and $30 \mathrm{phr}$ of MWCNTs, respectively. From Figure 2 it can be pointed out that at low strains the filled systems dis- 


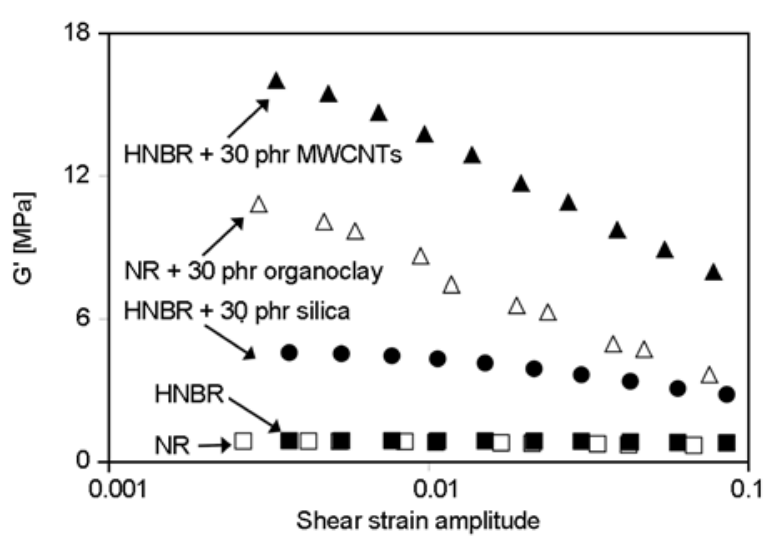

Figure 2. Dynamic storage modulus in shear mode at $1 \mathrm{~Hz}$ plotted against strain amplitude for HNBR- and NR- nanocomposites at 0 and $30 \mathrm{phr}$ of filler content

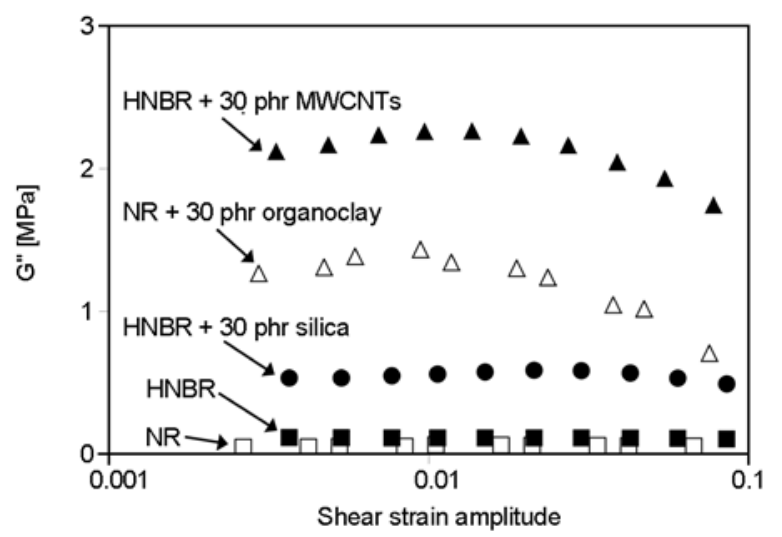

Figure 3. Dynamic loss modulus in shear mode at $1 \mathrm{~Hz}$ plotted against strain amplitude for HNBR- and NR-nanocomposites at 0 and 30 phr of filler content

play the typical non-linear behaviour (Payne effect) that consists in a decrease of the storage modulus with increasing strain amplitude. MWCNTs-filled system exhibits a stronger stiffening effect and a larger non-linearity effect compared to silica-filled HNBR. The storage and loss moduli obtained for NR and NR with $30 \mathrm{phr}$ organoclay are taken from ref. [6]. It is interesting to notice that, although the matrices have similar storage moduli, MWCNT improves the stiffness of HNBR far more than organoclay at the same filler loading ( $30 \mathrm{phr}$ ). For example, by considering the storage moduli at 0.003 of shear strain amplitude, it turns out that $30 \mathrm{phr}$ of silica improves 5 times the stiffness of its matrix, organoclay 13 times and MWCNTs 18 times. This efficiency of MWCNT is most probably linked with its dispersion and high aspect ratio. Further, MWCNTs are found to induce in the matrix the highest increase of energy dissipation, with respect to the

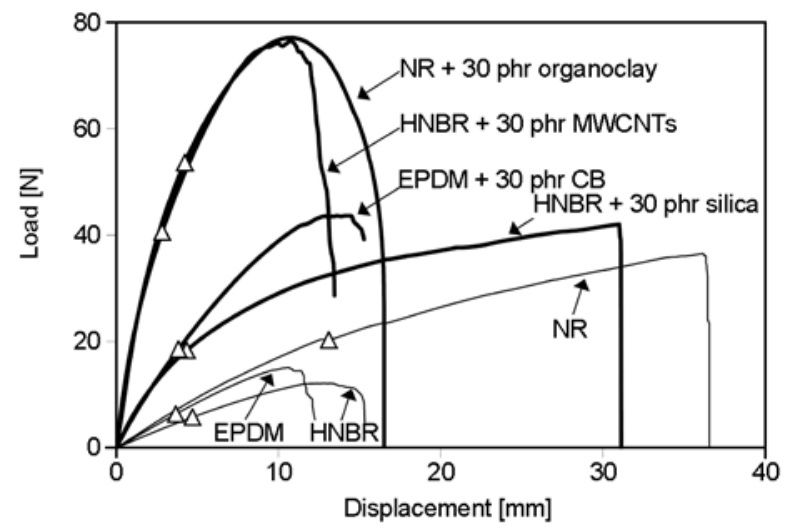

Figure 4. Load-displacement curves obtained from fracture tests on composites filled with $30 \mathrm{phr}$ of fillers (thick lines) and of the corresponding neat matrixes (HNBR, NR and EPDM rubber, thin lines). Open triangles indicate the point at $\mathrm{CTOD}^{\star}=0.1 \mathrm{~mm}$

other fillers investigated: this effect can be observed by the behaviour of the loss modulus vs strain amplitude plotted in Figure 3.

Tensile tests carried out on EPDM based rubbers provided the following elastic moduli, evaluated as the slope of the stress-strain curve at very small tensile strains: $1.7 \pm 0.05,4.7 \pm 0.20,7.1 \pm 0.09$ and 8.4 $\pm 0.20 \mathrm{MPa}$ for EPDM filled with $0,30,45$ and $60 \mathrm{phr}$ of $\mathrm{CB}$, respectively.

The raw results obtained from fracture mechanics tests are the load-displacement curves. Figure 4 shows characteristic load vs displacement traces obtained from fracture tests on SENT specimens of different materials: the neat matrices (EPDM and HNBR) and the samples filled with $30 \mathrm{phr}$ of nanofiller, EPDM with CB, HNBR with silica and MWCNTs. The curves of NR and NR filled with $30 \mathrm{phr}$ organoclay, obtained under the same experimental conditions [5], were inserted in Figure 4 for sake of comparison. The points of fracture initiation, assigned to $\mathrm{CTOD}^{\star}=0.1 \mathrm{~mm}$, are displayed on the curves by open triangles.

By considering the curves of the neat matrices, it can be observed that at small displacement values all the three materials have a similar behaviour, but NR shows a maximum displacement that exceeds more than twice those of the other matrices. Also the onset of fracture of NR occurs at a higher displacement than for the unfilled HNBR and EPDM rubbers. By the comparison of the curves of MWCNT and nano-silica filled HNBR, it can be seen from the initial slope of these curves that MWCNTs enhance the stiffness of HNBR speci- 
men more than silica nanoparticles. This result is in agreement with the trend of $G^{\prime}$ values at small strains obtained by DMTA experiments.Further, although MWCNT filling increases the maximum load reached during the test, the maximum displacement is reduced with respect to the matrix. This is characteristic for discontinuous fibrous reinforcements in all polymer composites. By contrast, the silica nanoparticles cause an increase of the maximum displacement. By observing the load-displacement curve related to the EPDM rubber filled with $\mathrm{CB}$, it appears that $30 \mathrm{phr}$ of $\mathrm{CB}$ within $\mathrm{EPDM}$ produces the same fracture behaviour as silica within HNBR, until the point of fracture initiation. With reference to NR filled with organoclay, surprisingly its loading curve follows faithfully that of HNBR reinforced by MWCNTs, though the onset of fracture of the NR system occurs at a larger displacement.

$J_{\text {Ic }}$ values, evaluated by Equation (1) at $\mathrm{CTOD}^{\star}=$ $0.1 \mathrm{~mm}$ and averaged over the results of three tests, are reported in Figure 5. The results of HNBR filled with silica nanoparticles (open circles) and MWCNTs (black circles), CB filled EPDM rubber (full triangles) and organoclay filled NR (full squares) [5] are plotted in Figure 5 as a function of the filler content.

Figure 5 provides an interesting comparison of $J_{\text {Ic }}$ values obtained for various rubbers containing different fillers. It can be seen that neat HNBR and EPDM rubber (see values at 0 phr filler content) have a comparable fracture resistance. At $10 \mathrm{phr}$ filler, MWCNTs increase fracture resistance of HNBR slightly more than silica nanoparticles do. However, the fracture resistance of HNBR filled with $30 \mathrm{phr}$ MWCNTs outperforms both that of

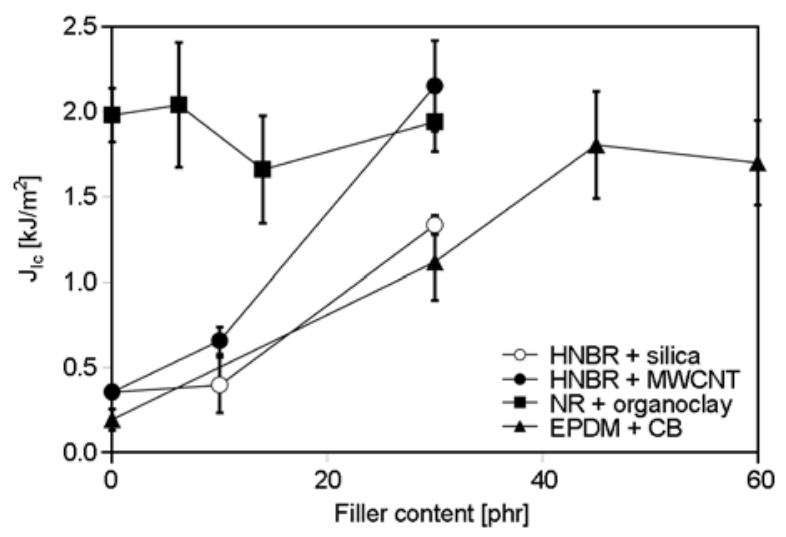

Figure 5. $J_{\text {Ic }} v s$ filler content for the various elastomeric composites investigated
HNBR with $30 \mathrm{phr}$ silica and that of EPDM with $30 \mathrm{phr}$ CB. Moreover, by comparing the HNBR/ MWCNTs and EPDM/CB systems, the results clearly indicate that a substantially higher amount of $\mathrm{CB}$ than MWCNT is required to achieve a comparable level of fracture resistance. It also turns out that the fracture resistance of MWCNTs filled HNBR is comparable to that of NR filled with 30 phr organoclay. It is worthwhile to note that the fracture resistance of NR-based systems can be strongly influenced by strain-induced crystallization, and thus it cannot be only attributed to reinforcing effect of the filler. In fact $J_{\text {Ic }}$ of NR is practically not affected by the incorporation of organoclay up to a content of $30 \mathrm{phr}$, which could be linked to a dominant effect of strain-induced crystallization. This hypothesis is supported by literature works, that analyze the significant fracture resistance enhancement of NR-based systems promoted by strain induced crystallization (see for example ref. [12]).

Further, the fracture resistance of HNBR and EPDM based systems was analysed during the process of fracture propagation. As described in the experimental section, $J$ values are calculated for several points on the load-displacement curve after the onset of fracture and the corresponding CTOD ${ }^{\star}$ values are measured on the photos of the crack tip taken during the fracture test. Some examples of $J$ vs $\mathrm{CTOD}^{\star}$ curves ( $J_{\mathrm{R}}$ curves) are shown in Figure 6, where $J_{\mathrm{R}}$ curves of the neat matrices, HNBR and EPDM, and of the corresponding composites added with $30 \mathrm{phr}$ filler are compared. It can be observed that $J_{\mathrm{R}}$ curves of the matrices are almost overlapping, and the curve referred to the $30 \mathrm{phr} \mathrm{CB}$ filled EPDM is very close to that of the $30 \mathrm{phr}$ silica filled HNBR sample. By contrast, it appears that at $30 \mathrm{phr}$

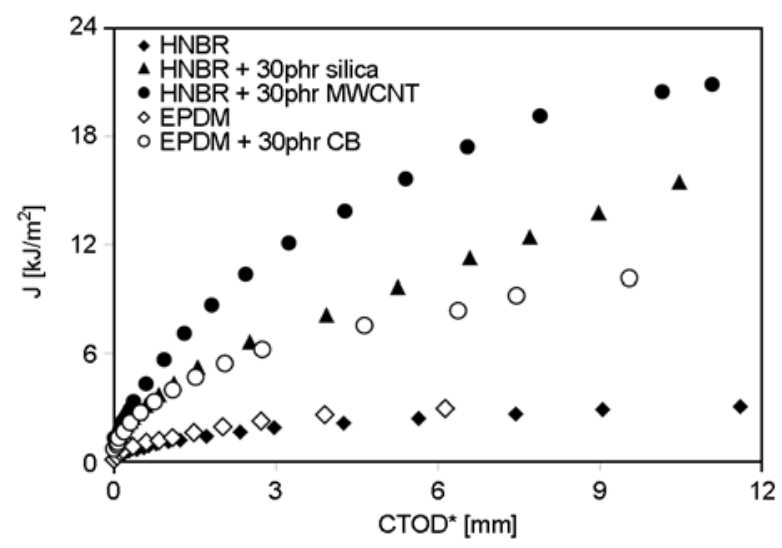

Figure 6. J-resistance curves of HNBR- and EPDM- based nanocomposites 
filler content HNBR with MWCNTs achieves higher levels of $J$ with respect to the other systems filled with $\mathrm{CB}$ or silica. This underlines the higher efficiency of MWCNTs, with respect to the other fillers, in enhancing the resistance to both fracture initiation and propagation.

It must be pointed out that a reliable comparison of $J$ values of the different materials during fracture propagation should be performed at the same crack advancement, whereas $\mathrm{CTOD}^{\star}$ parameter, used to plot $J_{\mathrm{R}}$ curves in this work, though related to $\Delta a$, is also dependent on the elastic properties of the material. However, it is still possible to compare the resistance to fracture propagation of materials with different deformability by the slope of the $J_{\mathrm{R}}\left(\mathrm{CTOD}^{\star}\right)$ curve at $\mathrm{CTOD}^{\star}=0 \mathrm{~mm}$. Then a $T_{\mathrm{J}}$ parameter, termed tearing modulus, as proposed in [5] is defined as Equation (2):

$$
T_{\mathrm{J}}=\left.\frac{\mathrm{d} J}{\mathrm{~d}\left(\mathrm{CTOD}^{\star}\right)}\right|_{\mathrm{CTOD}^{\star}=0}
$$

By this parameter the resistance to fracture propagation of different materials is evaluated at the same stage of the fracture process, i.e. at the very beginning of the process.

Figure 7 shows the values of the tearing modulus plotted as a function of the filler content, for the various rubber based composites. $T_{\mathrm{J}}$ values of NR filled with organoclay systems published in ref. [5] are also shown for comparison.

Concerning HNBR based systems, MWCNTs show a higher efficiency in improving the resistance to fracture propagation with respect to silica nanoparticles, since they increase the tearing modulus, as previously defined, even at low filler contents. Note that MWCNTs increase three times the tearing

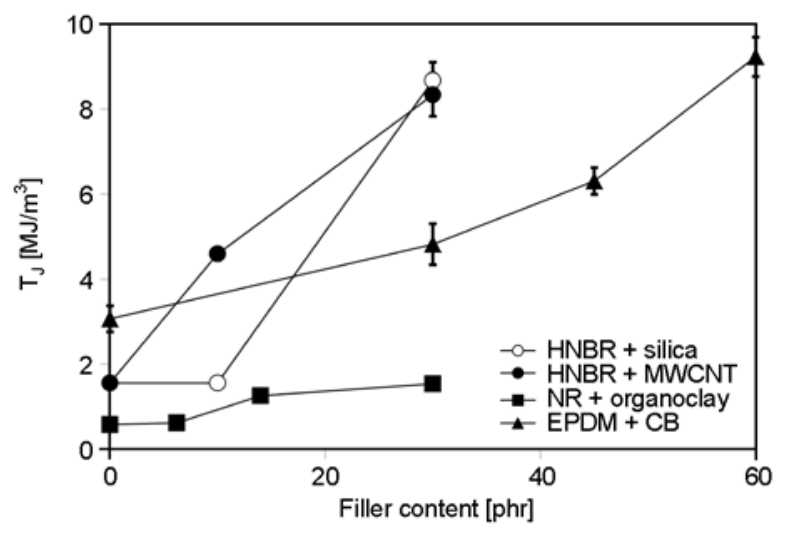

Figure 7. Tearing modulus, $T_{\mathrm{J}}$, vs filler content for the various elastomeric composites investigated modulus of HNBR at $10 \mathrm{phr}$ loading, while the effect of silica at the same filler content is negligible. Figure 7 indicates that $T_{\mathrm{J}}$ value of NR, which is lower than that of the other neat rubbers analysed, is only slightly increased by the addition of the organoclay. This is a further, however, still indirect confirmation on the large effect of strain-induced crystallization which does not take place at this stage. One can see that CB increases remarkably the $T_{\mathrm{J}}$ values of EPDM rubber only at high filler contents. A least $30 \mathrm{phr}$ of $\mathrm{CB}$ is required to increase the resistance to crack propagation of the EPDM rubber in order to reach the same level produced by $10 \mathrm{phr}$ of MWCNT in HNBR. Thus, the results of Figure 7 evidence as a whole the high efficiency of MWCNTs to enhance the resistance of elastomeric systems to crack propagation.

\section{Conclusions}

This work was devoted to characterize the strain softening and the fracture resistance of elastomer based nanocomposites making use of the J-integral approach. The rubber matrices, viz. NR, EPDM and HNBR, were filled with various amounts of MWCNT, organoclay, silica and CB.

While the matrices showed similar shear modulusshear strain traces, the storage modulus of the composite containing MWCNT exhibited larger nonlinearity and stronger reinforcing effect in the whole range of strain amplitude explored than organoclay and silica.

Results from the single-specimen J-testing methodology highlighted that MWCNT is the most efficient filler with respect to both crack initiation and propagation. Accordingly, similar fracture resistance data, i.e. $J_{\text {Ic }}$ and $T_{\mathrm{J}}$ values, can be obtained with smaller amounts of MWCNT than with other fillers.

Although this investigation was not extensively developed by systematically varying material composition and morphology, the results bring to light that the J-testing methodology used is a straightforward tool to check recipe related changes with respect to crack initiation and propagation resistance.

\section{References}

[1] Thomas S., Stephen R.: Rubber nanocomposites: Preparation, properties and applications. Wiley, Singapore (2010). 
[2] Mittal V., Kim J. K., Pal K.: Recent advances in elastomeric nanocomposites. Springer, Berlin (2011).

[3] Galimberti M.: Rubber-clay nanocomposites. WileyVCH, Weinheim (2011).

[4] Reincke K., Grellmann W., Heinrich G.: Investigation of mechanical and fracture mechanical properties of elastomers filled with precipitated silica and nanofillers based upon layered silicates. Rubber Chemistry and Technology, 77, 662-677 (2004).

DOI: $10.5254 / 1.3547843$

[5] Ramorino G., Agnelli S., De Santis R., Riccò T.: Investigation of fracture resistance of natural rubber/clay nanocomposites by $J$-testing. Engineering Fracture Mechanics, 77, 1527-1536 (2010).

DOI: $10.1016 /$ j.engfracmech.2010.04.021

[6] Ramorino G., Bignotti F., Conzatti L., Ricco T.: Dynamic and viscoelastic behavior of natural rubber/ layered silicate nanocomposites obtained by melt blending. Polymer Engineering and Science, 47, 1650-1657 (2007).

DOI: $10.1002 /$ pen.20849

[7] Ramorino G., Bignotti F., Pandini S., Riccò T.: Mechanical reinforcement in natural rubber/organoclay nanocomposites. Composites Science and Technology, 69, 1206-1211 (2009).

DOI: 10.1016/j.compscitech.2009.02.023
[8] Xu D., Karger-Kocsis J., Schlarb A. K.: Rolling wear of EPDM and SBR rubbers as a function of carbon black contents: Correlation with microhardness. Journal of Materials Science, 43, 4330-4339 (2008).

DOI: $10.1007 / \mathrm{s} 10853-008-2637-7$

[9] Felhős D., Karger-Kocsis J., Xu D.: Tribological testing of peroxide cured HNBR with different MWCNT and silica contents under dry sliding and rolling conditions against steel. Journal of Applied Polymer Science, 108, 2840-2851 (2008).

DOI: 10.1002/app.27624

[10] Xu D., Karger-Kocsis J., Schlarb A. K.: Friction and wear of HNBR with different fillers under dry rolling and sliding conditions. Express Polymer Letters, 3, 126-136 (2009).

DOI: 10.3144 /expresspolymlett.2009.16

[11] Agnelli S., Baldi F., Riccò T.: A tentative application of the energy separation principle to the determination of the fracture resistance $\left(J_{\mathrm{Ic}}\right)$ of rubbers. Engineering Fracture Mechanics, in press (2012).

[12] Lee D. J., Donovan J. A.: Microstructural changes in the crack tip region of carbon-black-filled natural rubber. Rubber Chemistry and Technology, 60, 910-923 (1987).

DOI: $10.5254 / 1.3536164$ 